\title{
RHINOLOGY
}

\section{A comparison of two endoscopic techniques for the treatment of antrochoanal polyps}

\author{
Trattamento chirurgico dei polipi antrocoanali: due tecniche endoscopiche a confronto \\ Hasan Ibrahim Al-Balas ${ }^{1}$, Paolo Farneti², Andrea Bellusci², Francesco Maria Crocetta ${ }^{2}$, Giacomo Sollini ${ }^{3}$, \\ Ernesto Pasquini ${ }^{3}$ \\ ${ }^{1}$ Faculty of Medicine, Yarmouk University, Irbid, Jordan; ${ }^{2}$ Bologna University Medical School - Sant'Orsola-Malpighi Hospital, \\ Bologna, Italy; ${ }^{3}$ Azienda Unità Sanitaria Locale di Bologna, ENT Department Bologna, Italy
}

\begin{abstract}
SUMMARY
An antrochoanal polyp (ACP) is a benign sinonasal lesion that originates from the mucosa of the maxillary sinus. In order to avoid any recurrence of disease, it is important to choose the best surgical approach for removal of ACP with respect to the site of attachment within the maxillary sinus walls. A retrospective cohort study was carried out by analysing a database of 82 patients who were operated on for ACPs in the Ear, Nose and Throat (ENT) clinics of both Sant'Orsola-Malpighi Polyclinic Hospital and Bellaria Hospital in Bologna, Italy from January 2001 to November 2017 to compare the rate of recurrence of ACPs after surgical removal using two different approaches. The first technique was endoscopic antrochoanal polypectomy with middle meatal antrostomy and the second was endoscopic antrochoanal polypectomy combined with both middle meatal antrostomy and a minimal access through the inferior meatus. A total of 49 patients were operated on with an endoscopic polypectomy with middle meatal antrostomy and $18.4 \%$ experienced a recurrence. The remaining 33 patients underwent endoscopic polypectomy with combined middle meatal antrostomy and access through the inferior meatus with a recurrence rate of $3 \%$. The difference between the two groups was statistically significant $(\mathrm{p}=0.0441)$. The strategy of the authors, namely combining medial antrostomy with a small inferior meatus access, was associated with a lower rate of recurrence and no increased morbidity in the short- or long-term.
\end{abstract}

KEY WORDS: antrochoanal polyp, endoscopic sinus surgery, middle meatus antrostomy, recurrence

\section{RIASSUNTO}

Il polipo antrocoanale (ACP) è una lesione benigna che origina dalla mucosa del seno mascellare. Al fine di evitare la recidiva chirurgica della patologia è importante scegliere il miglior approccio chirurgico per la rimozione del ACP a seconda del suo sito di attacco all'interno del seno mascellare. Uno studio retrospettivo è stato condotto analizzando il database di 82 pazienti operati per ACP presso le cliniche Otorinolaringoiatriche dell'Ospedale Sant'Orsola-Malpighi e dell'Ospedale Bellaria di Bologna, da gennaio 2001 a novembre 2017 al fine di confrontare il tasso di recidiva dopo la rimozione chirurgica utilizzando due differenti tipi di approccio. Il primo tipo prevede una polipectomia endoscopica attraverso un'antrostomia media mentre il secondo approccio è stato eseguito attraverso una rimozione endoscopica combinata con meatotomia media e un accesso di minima attraverso il meato inferiore. Quarantanove pazienti sono stati operati con il primo tipo di approccio con un tasso di recidiva del 18,4\% mentre $i$ rimanenti 33 sono stati sottoposti a un approccio combinato con un tasso di recidiva del 3\%. La differenza fra i due gruppi è risultata essere statisticamente significativa $(p=0,0441)$. La strategia di combinare un accesso tradizionale con un accesso di minima attraverso il meato inferiore ha mostrato un minor tasso di recidiva senza un incremento della morbilità post-operatoria a breve e a lungo termine.

PAROLE CHIAVE: polipo antrocoanale, chirurgia endoscopica nasosinusale, antrostomia media, recidiva
Received: April 23, 2019

Accepted: December 20, 2019

Correspondence

Paolo Farneti

via Pancaldi 1, 40138 Bologna, Italy

Tel. +39051391017

E-mail: farnetipaolo@gmail.com

Funding

None.

Conflict of interest

The Authors declare no conflict of interest.

How to cite this article: Al-Balas HI, Farneti P, Bellusci A, et al. A comparison of two endoscopic techniques for the treatment of atrochoanal polyps. Acta Otorhinolaryngol Ital 2020;40:290-296. https:// doi.org/10.14639/0392-100X-N0259

(C) Società Italiana di Otorinolaringoiatria e Chirurgia Cervico-Facciale

\section{c) (i) $\$$}

This is an open access article distributed in accordance with the CC-BY-NC-ND (Creative Commons Attribution-NonCommercial-NoDerivatives 4.0 International) license. The article can be used by giving appropriate credit and mentioning the license, but only for non-commercial purposes and only in the original version. For further information: https:// creativecommons.org/licenses/by-nc-nd/4.0/deed.en 


\section{Introduction}

Antrochoanal polyps (ACPs) are benign polypoid lesions that originate from the mucosa of the maxillary sinus, extending into the nasal cavity through the natural sinus ostium or through its accessory ostium to reach the choana posteriorly ${ }^{1}$. Although Killian described the lesion in detail in $1906^{2}$, it was reported for the first time by Palfijn in $1753^{3}$.

Clinically, an ACP appears as a bright, grey or pinkish mass in the middle meatus and nasal cavity protruding posteriorly to the choana. Computed tomography (CT) can help to assess its nature, showing a soft tissue mass filling the maxillary sinus and growing through the accessory ostium into the middle meatus and the posterior choana ${ }^{4}$.

No studies on the efficacy of medical therapy for ACP have been reported ${ }^{5,6}$, and the mainstay of treatment is still considered surgery as already proposed by Stammberger in his "Polyposis Nasi" classification ${ }^{7}$. In particular, the endoscopic technique has become the most widely accepted approach ${ }^{8,9}$, even in children ${ }^{10}$. To prevent recurrence of the disease, it is important to avoid a simple polypectomy and to remove the underlying mucosa at the site of origin of the ACP with minimal interruption of the normal sinus physiology ${ }^{6}$. However, it is not always possible to determine the point of attachment preoperatively due to the presence of coexistent sinonasal mucosal disease ${ }^{4,6}$ and, consequently, to precisely plan the most suitable surgical approach.

In the past, the Caldwell-Luc procedure was used as the primary modality of treatment; however, the risk of damaging tooth development and the growth centres of the maxilla in children together with frequent post-operative cheek anaesthesia and cheek swelling affected its popularity ${ }^{11}$.

The role of endoscopic sinus surgery (ESS) has been enhanced by the introduction of angled optics and powered instrumentation, with particular regard to angled microdebrider blades, which provide a good surgical field by shaving and removing the soft tissue, allowing the intact mucosa to be spared during dissection around the point of attachment ${ }^{12}$. Nevertheless, it is not always possible to locate and reach the maxillary stalk of the ACP purely endoscopically, especially when it is on the anterior or inferior wall of the maxillary sinus. For this reason, different surgical approaches have been proposed in association with the endoscopic technique in order to avoid recurrence due to incomplete removal of the polyp by providing less morbidity and a lower rate of complications compared to a CaldwellLuc procedure. Better visualisation and access to the maxillary sinus can be obtained by combining ESS with a mini-Caldwell-Luc procedure ${ }^{13}$, canine fossa puncture ${ }^{6,14,15}$, inferior meatal antrostomy ${ }^{16,17}$, to a transnasal prelacrimal recess approach (suggested for revision surgery) ${ }^{18}$ or ESS with wide middle meatal antrostomy ${ }^{8}$.

The aim of the present study was to compare the rate of recurrence of two different approaches for treatment of ACP. The first technique was endoscopic antrochoanal polypectomy with middle meatal antrostomy and the second was an endoscopic antrochoanal polypectomy combined with both middle meatal antrostomy and a minimal access through the inferior meatus. As for secondary aims, symptoms, age, gender, time of follow up, association with atopy and postoperative complications were assessed in the patients treated.

\section{Materials and methods}

This retrospective study was carried out by analysing the database of 82 patients who were operated on for ACPs in the Ear, Nose and Throat (ENT) clinics of both Sant'Orsola-Malpighi Polyclinic Hospital and Bellaria Hospital in Bologna, Italy from January 2001 to November 2017. Factors including age, gender, atopy, associated symptoms, physical findings, imaging findings, surgical techniques, follow-up and management of recurrence were retrospectively studied.

An endoscopic examination was carried out in all patients, revealing the presence of a polypoid mass extending from the middle meatus to the choana. In all cases, radiological evaluation by $\mathrm{CT}$ of the paranasal sinuses was carried out. CT confirmed the features of the ACPs, which appeared as unilateral soft-tissue masses without evidence of bony erosion or soft tissue extension (Fig. 1). The concomitant presence of a septal deviation, ethmoidal sinusitis and/or concha bullosa of the middle turbinate were identified (Tab. I).

In the present study, there were no preoperative selection criteria to determine the type of surgery. When the ACPs originated from the posterior or lateral wall of the maxillary sinus, a middle meatal antrostomy was usually satisfactory to reach the site of origin. Otherwise, in patients in whom it was not possible to precisely locate the site of origin of the ACP, association with a minimal inferior meatal access was preferred. However, the inferior access was frequently not feasible in young children because the maxillary sinus was not perfectly pneumatised. In these cases, it was impossible to reach the sinus through the inferior meatus because of the projection of the alveolar bone at this level. Moreover, in these cases, the inferior access would not have been useful because a small maxillary sinus can be completely dominated using a traditional middle meatal antrostomy. Postoperatively, all patients were followed up in an outpatient setting, with nasal endoscopy after 1 month, 3 months and 6 months, and then every year. 

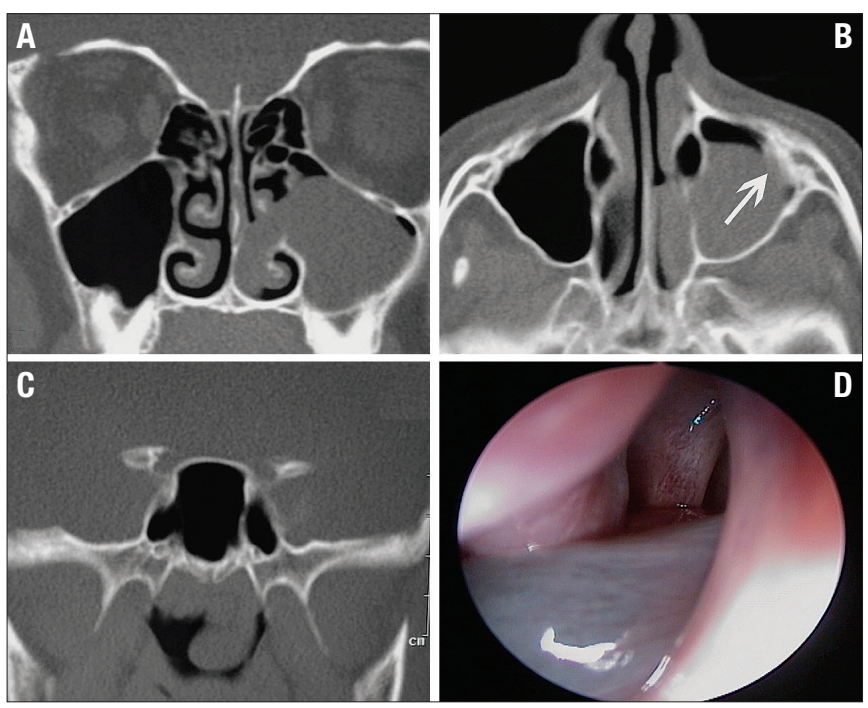

Figure 1. (A) Coronal computed tomography (CT) scan illustrating an opacified left maxillary sinus with antrochoanal polyp extending into the nasal cavity; (B) axial CT scan showing that the origin is from the lateral wall of the maxillary sinus (white arrow); (C) posterior view of the CT scan showing the extension into the choana; (D) endoscopic view showing a whitish mass originating from the maxillary sinus, exiting from the accessory ostium and extending into the nasal cavity.

Table I. Preoperative CT findings.

\begin{tabular}{lcc} 
Preoperative findings & Patients & $\%$ of patients \\
SD & 10 & $12.2 \%$ \\
CB & 6 & $7.3 \%$ \\
Ethmoidal sinusitis & 10 & $12.2 \%$ \\
SD and CB & 4 & $4.9 \%$ \\
SD and ethmoidal sinusitis & 2 & $2.4 \%$ \\
CB and ethmoidal sinusitis & 4 & $4.9 \%$ \\
No associated pathology & 46 & $56.1 \%$ \\
\hline
\end{tabular}

CT: computed tomography; SD: septal deviation; CB: concha bullosa.

\section{Surgical procedure}

In this study, two techniques for the removal of ACPs were compared with regards to recurrence rates. The first technique consisted of an endoscopic polypectomy with middle meatal antrostomy (standard approach); the second technique consisted of an endoscopic polypectomy with middle meatal antrostomy plus minimal access through the inferior meatus (combined approach). All surgical procedures were performed by two experienced surgeons. A hypotensive general anaesthesia technique was used for all patients, with supine position and the head was slightly elevated. Cotton mixed with decongestant agents was inserted into the nose for 10 minutes before surgery. Different angled rigid $\left(30^{\circ}, 70^{\circ}\right) 4 \mathrm{~mm}$ endoscopes were used to inspect the nose and determine the extent of the polyp. In both techniques, removal of the nasal part of the ACP was followed by retrograde uncinectomy and a large middle meatal antrostomy to access the maxillary portion and extract the antral part using angled instruments or a curved microdebrider. The difference between the two techniques consisted of how the site of origin was approached.

With the first technique, once the antral part of the ACP was removed, the point of attachment was localised using angled endoscopes $\left(30^{\circ}, 70^{\circ}\right)$, and the underlying mucosa was then removed using an angled instrument or curved microdebrider $\left(120^{\circ}\right)$ (Fig. 2). In cases where it was impossible to adequately localise the point of attachment with the standard approach, the combined approach was performed. In addition to middle meatus antrostomy, a small opening to the inferior meatus was also made with this technique (Fig. 3). After medialising the inferior turbinate, the Hasner's valve was localised to avoid any injury to the lacrimal pathway. A mucosal flap was elevated with a vertical incision on the medial wall of the maxillary sinus laterally to the inferior turbinate and a small opening was created with a "curette" through the medial bony wall of the maxillary sinus. An angled microdebrider or a Weil forceps was inserted through this opening under direct vision with the endoscopes $\left(30^{\circ}\right.$ or $\left.70^{\circ}\right)$ introduced through the middle antrostomy to remove the point of attachment of the ACP. The endoscope could also be introduced through the inferior access for a better view of the walls of the maxillary sinus after ACP removal to handle any possible residue. At the end of the procedure, the inferior antrostomy
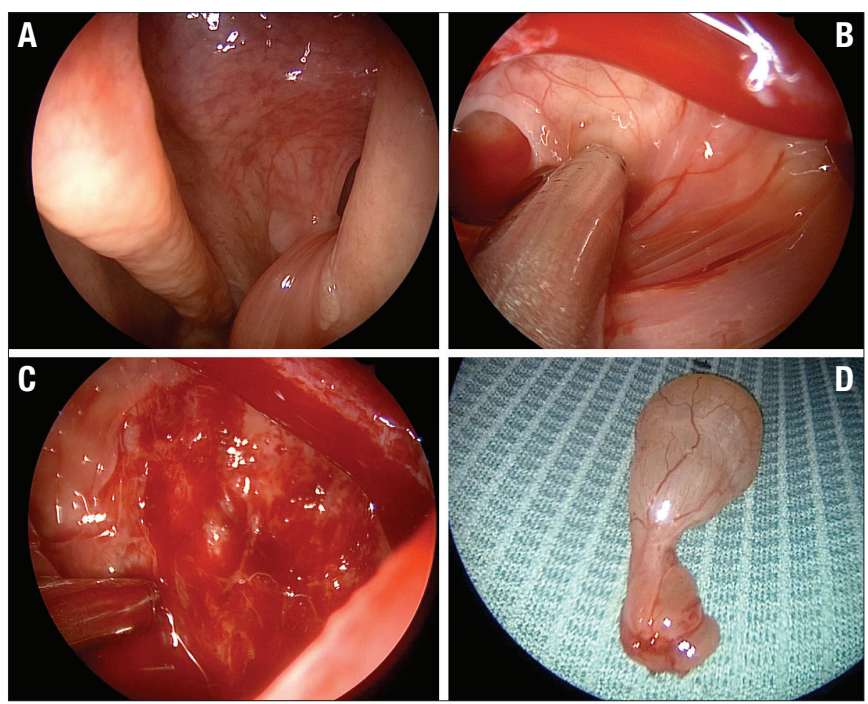

Figure 2. Removal of an antrochoanal polyp (ACP) using the standard approach. (A) ACP exiting from the accessory ostium of the left maxillary sinus; (B) localisation of the point of attachment on the lateral wall before dissection with a curved debrider blade; (C) complete removal of the mucosa at the point of attachment; (D) external view of the ACP. 

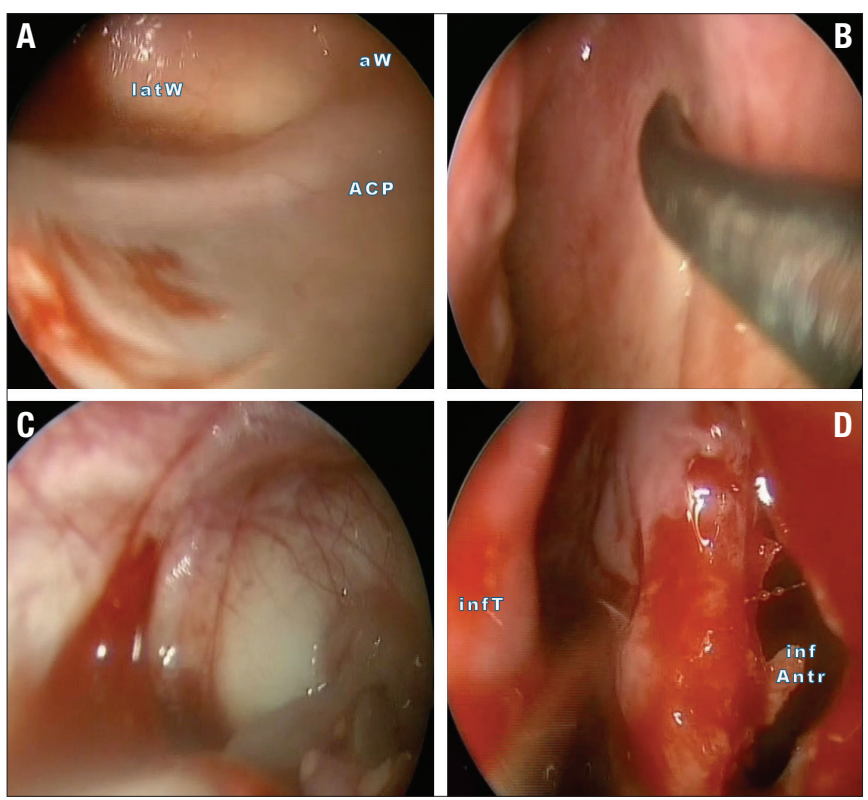

Figure 3. Endoscopic removal of an antrochoanal polyp (ACP) originating from the anterior wall of the maxillary sinus using a combined approach. (A) endoscopic view with a $70^{\circ}$ endoscope through the middle meatus to show the point of attachment of the ACP on the anterior wall; LatW (lateral wall), aW (anterior wall), ACP (antrochoanal polyp point of attachment); (B) point of incision on the lateral wall of the inferior meatus to carry out the inferior minimal access; (C) endoscopic view with a $70^{\circ}$ endoscope through the middle meatus showing the tip of the microdebrider inserted through the small antrostomy from the inferior meatus while drilling the site of attachment of the ACP; (D) endoscopic view with $0^{\circ}$ endoscope showing the inferior meatus access in the inferior meatus at the end of the procedure; infT (inferior turbinate), inf antr (inferior antrostomy).

access was covered with a previously prepared mucosal flap, and the inferior turbinate was lateralised, ensuring complete haemostasis and avoiding any recirculation from the inferior access. In both techniques, nasal packing with one short Merocel $^{\circledR}$ was performed.

The nasal packing was removed on the first postoperative day and patients were discharged; daily nasal douching was also prescribed. They were also prescribed topical or systemic steroid therapy if oedema of the maxillary sinus mucosa was detected at the first follow-up visit one month after surgery.
Statistical analysis

Data were recorded in a Microsoft Excel (Redmond, WA, USA) spreadsheet and analysed using SPSS version 16.0. Statistical significance was assessed using a two-tailed Fisher's exact test ( $\mathrm{p}<0.05$ were considered significant).

This study was approved by the Local Institutional Review Board of Sant'Orsola-Malpighi Hospital in Bologna (194/2016/O/OssN), and informed consent was obtained from each patient.

\section{Results}

Of the 82 patients, $50(61 \%)$ were male and $32(39 \%)$ were female. Ages ranged from 6 to 87 years with a mean age of 32 years. Twenty-eight patients were 16 years old or younger. Of the 82 patients, 16 with recurrent ACPs were referred to us from other centres. In $61 \%$ of patients, the ACP was located on the right side and, in $39 \%$ of patients, it was located on the left side.

Nasal obstruction was the most common symptom in $86.6 \%$ of the patients, followed by rhinorrhea (39\%), snoring (12.2\%), headache (9.8\%), epistaxis (3.7\%), anosmia (2.4\%) and dysphagia (1.2\%). However, the most frequent presenting complaint was a combination of nasal obstruction with one or more other symptoms, followed by nasal obstruction alone; $48 \%$ of patients in the study suffered from atopic rhinitis and/or asthma. Of the 82 patients, 49 patients were operated on using a standard approach, and the other 33 underwent a combined approach. Of the 49 patients, 9 had a recurrence of ACPs while, of the 33 patients, only one had a recurrence. At endoscopic follow-up, recurrence was identified as a polypoid mass originating from the maxillary sinus not responding to medical therapy. The difference between the two groups was statistically significant $(p=0.0441)$ (Tab. II).

The study involved 28 patients who were 16 years old or younger. Of these 28 patients, a total of 14 were operated on using the standard approach and, of these, 5 developed a recurrence. On the other hand, 14 patients underwent endoscopic polypectomy with the combined approach, and none developed a recurrence. The difference between the two groups was statistically significant $(\mathrm{p}=0.0407)$.

Table II. Comparison of recurrences between the standard and combined approaches.

\begin{tabular}{lccc} 
& $\begin{array}{c}\text { No. of patients operated on using } \\
\text { a standard approach }\end{array}$ & $\begin{array}{c}\text { No. of patients operated on using } \\
\text { a combined approach }\end{array}$ & Total No. of patients \\
No recurrence & 40 & 32 & 72 \\
Recurrence & 9 & 1 & 10 \\
Total & 49 & 33 & 82 \\
$\%$ of recurrence & $18.4 \%$ & $3 \%$ & $12.2 \%$ \\
\hline
\end{tabular}


The ACPs in the maxillary sinus were divided into five groups depending on the origin and attachment sites determined intraoperatively as reported in Table III. In 34 patients, the exact origin was missing in the patient's chart. There were no significant associations between the type of surgery for each attachment site and the recurrence rate.

Follow-up ranged from 19 to 106 months (average 41 months, median 37 and standard deviation 19.7). Ten patients had a follow-up of less than 24 months; of these, 3 had undergone a combined approach.

The earliest case of recurrence was documented at 11 months postoperatively. Of the 10 patients with recurrence; 5 underwent revision surgery with a standard approach, 4 patients underwent a combined approach (including the patient who had already been operated on with this approach) and 1 patient refused revision surgery. None of these patients had a second recurrence after a follow-up ranging from 26 to 84 months (average 46 months).

Sixty-six of the 82 patients received topical nasal steroid therapy, and 7 received combined topical and systemic steroid therapy.

No major complications were reported after surgery or at follow-up. Two patients operated on with the combined approach had an anterior synechia between the nasal septum and the inferior turbinate which was treated with an office procedure. None had a recurrence of the ACP. In all cases operated on using the combined approach, access through the inferior meatus was found to be closed at follow-up. None of the patients in either group presented epiphora postoperatively due to the preservation of the lacrimal sac and Hasner's valve.

\section{Discussion}

An antrochoanal polyp is a benign sinonasal lesion that originates from the mucosa of maxillary sinus. Although ACPs can occur at any age ${ }^{9,19,20}$, they occur more frequently in children and young adults ${ }^{20,21}$. In the present series, $34.1 \%$ were 16 years old or younger. The majority of authors have observed that ACPs are more common in males ${ }^{22}$. Cook et al. reported rates of $70 \%$ in males and $30 \%$ in females ${ }^{19}$. In the present study, $61 \%$ of cases were male and $39 \%$ were female. However, other authors, such as Gendeh et al. ${ }^{17}$ and Kaushalt et al. ${ }^{23}$ found ACPs to be more prevalent in females with a male/female ratio of 1:1.5.

Nasal obstruction is the most common symptom of ACPs as was confirmed by Franche et al. who found that $83 \%$ of patients had nasal obstruction ${ }^{24}$ and also in the present study (86.6\% of patients had nasal obstruction). Although Cook et al. found a significant relationship with allergy and asthma among the 33 cases studied ${ }^{19}$, the majority of other researchers did not find any association with allergic disease or atopy ${ }^{25,26}$. Of the patients in the present study, $47.6 \%$ suffered from atopic rhinitis and/or asthma.

One of the unusual manifestations of ACPs is epistaxis. Patients presenting with this symptom should undergo additional examinations to exclude other possible causes, such as juvenile nasopharyngeal angiofibroma or sinonasal malignancies. In the present study, magnetic resonance imaging was performed in three patients who had epistaxis in order to rule out other differential diagnoses.

ACPs can be subdivided depending on the site of attachment within the maxillary sinus wall. Berg et al, concluded that the 15 cases of ACP which they studied had the site of origin on the inferolateral wall of the maxillary sinus ${ }^{27}$. Deka found that $45 \%$ of his cases had an attachment to the posterior medial wall of the antrum adjoining the posterior fontanelle, $40 \%$ of the polyps originated from the anteroinferior aspect of the antrum and, in 15\%, the site of origin could not be precisely evaluated ${ }^{28}$. In the present study, in $41.4 \%$ of cases, information regarding the site of origin was missing in the patient chart, $31.7 \%$ originated from the inferior wall, $12.2 \%$ from the anterior wall, $9.8 \%$ from the lateral wall and just $4.9 \%$ originated from the posterior wall.

Many surgical options for treating ACPs have been proposed to decrease the incidence of postoperative recurrence with minimal postoperative complications. All of these surgical options concentrate on a general principle

Table III. Comparison of recurrences considering the site of attachment of the ACP for each surgical approach.

\begin{tabular}{|c|c|c|c|c|c|c|}
\hline Site of attachment & $\begin{array}{l}\text { Total No. } \\
\text { of patients }\end{array}$ & $\begin{array}{l}\text { Standard } \\
\text { approach }\end{array}$ & Recurrence (\%) & $\begin{array}{l}\text { Combined } \\
\text { approach }\end{array}$ & Recurrence & $P$ value \\
\hline Not reported & 34 & 19 & $3(15.8 \%)$ & 15 & $1(6.7 \%)$ & 0.6128 \\
\hline Anterior wall & 10 & 5 & $1(20 \%)$ & 5 & 0 & 1.0000 \\
\hline Posterior wall & 4 & 4 & 0 & 0 & 0 & 1.0000 \\
\hline Lateral wall & 8 & 6 & $2(33 \%)$ & 2 & 0 & 1.0000 \\
\hline Inferior wall & 26 & 15 & $3(20 \%)$ & 11 & 0 & 0.2385 \\
\hline
\end{tabular}

ACP: atrochoanal polyp. 
which is how to reach the site of origin. One of the surgical options is simple polypectomy (removing the polyp using angled forceps from the maxillary cavity without concern for the site of origin). However, ACP recurrence is reported to be $25 \%$ after this type of procedure ${ }^{29}$. On the other hand, in the past, the Caldwell Luc procedure was considered to be the primary modality of treatment, but the significant risks to developing teeth and the bone growth centres of the maxilla in children was considered to be a substantial drawback of this type of surgery ${ }^{11}$. The endoscopic approach avoids swelling of the cheeks, decreases adverse effects on teeth and facial growth in children, and has a shorter hospitalisation time compared with the Caldwell-Luc procedure ${ }^{21}$. Overall, many authors agree with the effectiveness and safety of the endoscopic approach for the removal of ACPs ${ }^{8,9}$. In a study carried out by Franche et al., a recurrence rate of $6.9 \%$ was observed in 29 patients operated on using an endoscopic transnasal approach ${ }^{24}$. Freitas et al. managed 16 cases of ACPs with the same approach and reported recurrence in $12.5 \%{ }^{30}$, while Ozdek et al. recorded up to $22 \%$ of recurrences after middle meatal antrostomy alone ${ }^{21}$. In a series of paediatric patients operated on in three ENT Italian Departments, Pagella et al. reported $22 \%$ of recurrences on those operated on using a standard approach (12/42 patients) and $0 \%$ of recurrence in 4 cases treated with a combined endoscopic and canine fossa approach ${ }^{6}$. In the present study, the recurrence rate after endoscopic polypectomy with middle meatal antrostomy was $18.4 \%$, which is consistent with the majority of published reports.

Few authors used only inferior antrostomy to remove the antral portion of ACPs. In a study carried out by Gendeh et al., two of three patients operated on with an endoscopic intranasal polypectomy using an inferior antrostomy approach developed a recurrence after 1 year of follow-up ${ }^{17}$. Sato and Nakashima also used the same approach to remove the antral portion of ACPs; of the 10 patients enrolled in this study, none had a recurrence after a follow-up of 10 to 46 months ${ }^{16}$. In the present study, the recurrence rate after a combined approach was only $3 \%$ with complete closure of the medial wall of the maxillary sinus in the inferior meatus, thanks to the minimally invasive access carried out.

The main advantage of the present technique was to diminish the recurrence rate of ACPs with minimal perioperative complications; a statistically significant decrease from $18.4 \%$ with the standard to $3 \%$ with the new combined approach was reported with no significant major complications in either case. The advantage of this new approach was evident in situations where the origin of the ACPs was undetermined or was difficult to reach using traditional middle meatus antrostomy (anterior wall or inferior wall). Lee et al. performed endoscopic sinus surgery for ACPs originating posteriorly and inferiorly; on the other hand, for those originating from the lateral wall of the maxillary sinus, a combined (endoscopic and transcanine) approach was carried out. They reported a $76.9 \%$ success rate for those treated with endoscopic sinus surgery alone, and a $100 \%$ success rate with the combined approach ${ }^{14}$. In the present study, the success rate for ACPs originating inferiorly and posteriorly was $84.2 \%$ with the standard approach and $100 \%$ with the combined approach; for those originating from the lateral wall, the success rate was $66.6 \%$ with the standard approach and $100 \%$ with the combined approach.

Comoglu et al. have recently suggested a transnasal prelacrimal recess approach in patients with recurrent antrochoanal polyps with an $83 \%$ success rate (10/12); according to the authors, this method of treatment ensured good exploration of the sinus and easy access to the origin of the polyp ${ }^{18}$ despite a higher risk of damaging the lacrimal pathway.

Even if endoscopic polypectomy with inferior meatal antrostomy could be associated with the risk of developing synechia ${ }^{17}$ or epiphora in the present study, only two patients operated on with the combined approach had an anterior synechia which was treated with an office procedure.

\section{Limitations of the study}

The present study has some limitations, such as a heterogeneous age range and its retrospective nature which did not permit having a random selection of the surgical approach. An additional limitation was due to 10 patients having a follow-up period of less than 24 months. According to Chaiyasate, patients should be followed up for at least 2 years postoperatively in order to detect $95 \%$ of recurrences ${ }^{31}$. Multivariate analysis was not carried out due to the limited number of recurrences.

\section{Conclusions}

An antrochoanal polyp is a benign expansive inflammatory lesion with a high recurrence rate if not completely excised by removing the underlying mucosa at the site of origin. Therefore, the best surgical strategies should combine radical removal with low morbidity. Either the CaldwellLuc procedure or a medial maxillectomy are effective in lesion removal, but with higher morbidity. The strategy in the present study, namely combining medial antrostomy with a minimal access through the inferior meatus, showed a low rate of recurrence and no postoperative mid-term morbidity. 


\section{References}

1 Min YG, Chung JW, Shin JS, et al. Histologic structure of antrochoanal polyps. Acta Otolaryngol 1995;115:543-7. https://doi. org/10.3109/00016489509139364

2 Killian G. The origin of choanal polypi. Lancet 1906;168:81-2. https://doi.org/10.1016/S0140-6736(01)32583-7

3 Palfijn J. Anatomie chirurgicale. Paris: Cavelier, Guillaume; 1753.

4 Choudhury N, Hariri A, Saleh H, et al. Diagnostic challenges of antrochoanal polyps: a review of sixty-one cases. Clin Otolaryngol 2018;43:670-4. https://doi.org/10.1111/coa.12993

5 Maldonado M, Martines A, Alobid I, et al. The antrochoanal polyp. Rhinology 2004;42:178-82.

6 Pagella F, Emanuelli E, Pusateri A, et al. Clinical features and management of antrochoanal polyps in children: cues from a clinical series of 58 patients. Int J Pediatr Otorhinolaryngol 2018;114:87-91. https://doi.org/10.1016/j.ijporl.2018.08.033

7 Stammberger H. Surgical treatment of nasal polyps: past, present, and future. Allergy 1999;54(Suppl 53):7-11. https://doi. org/10.1111/j.1398-9995.1999.tb05031.x

8 Eladl HM, Shawky M. Endoscopic surgery in pediatric recurrent antrochoanal polyp, rule of wide ostium. Int J Pediatr Otorhinolaryngol 2011;75:1372-5. https://doi.org/10.1016/j.ijporl.2011.07.029

9 Frosini P, Picarella G, De Campora E. Antrochoanal polyp: analysis of 200 cases. Acta Otorhinolaryngol Ital 2009;29:21-6.

10 Galluzzi F, Pignataro L, Maddalone M, et al. Recurrences of surgery for antrochoanal polyps in children: a systematic review. Int $\mathbf{J}$ Pediatr Otorhinolaryngol 2018;106:26-30. https://doi.org/10.1016/j. ijporl.2017.12.035

11 Woolley AL, Clary RA, Lusk RP. Antrochoanal polyps in children. Am J Otolaryngol 1996;17:368-73. https://doi. org/10.1177/194589240101500507

12 Hong SK, Min YG, Kim CN, et al. Endoscopic removal of the antral portion of antrochoanal polyp by powered instrumentation. Laryngoscope 2001;111:1774-8. https://doi.org/10.1097/00005537200110000-00021

13 Atighechi S, Baradaranfar MH, Karimi G, et al. Antrochoanal polyp: a comparative study of endoscopic endonasal surgery alone and endoscopic endonasal plus mini-Caldwell technique. Eur Arch Otorhinolaryngol 2009;266:1245-8. https://doi.org/10.1007/s00405-0080890-7

14 Lee TJ, Huang SF. Endoscopic sinus surgery for antrochoanal polyps in children. Otolaryngol Head Neck Surg 2006;135:688-92. https:// doi.org/10.1016/j.otohns.2006.02.035

15 Sireci F, Nicolotti M, Battaglia P, et al. Canine fossa puncture in endoscopic sinus surgery: report of two cases. Braz J Otorhinolaryngol 2017;83:594-9. https://doi.org/10.1016/j.bjorl.2017.03.001

16 Sato K, Nakashima T. Endoscopic sinus surgery for chronic sinusitis with antrochoanal polyp. Laryngoscope 2000;110:1581-3. https://doi. org/10.1097/00005537-200009000-00036

17 Gendeh BS, Long YT, Misiran K. Antrochoanal polyps: clinical presentation and the role of powered endoscopic polypectomy. Asian J Surgery 2004;27:22-5. https://doi.org/10.1016/S1015-9584(09)60239-6

18 Comoglu S, Celik M, Enver N, et al. Transnasal prelacrimal recess approach for recurrent antrachoanal polyp. J Craniofac Surg 2016;27:1025-7. https://doi.org/10.1097/SCS.0000000000002699

19 Cook PR, Davis WE, McDonald R, et al. Antrochoanal polyposis: a review of 33 cases. Ear Nose Throat J 1993;72:401-2, 404-10.

20 Yuca K, Bayram I, Kiroglu AF, et al. Evaluation and treatment of antrochoanal polyps. J Otolaryngol 2006;35:420-3.

21 Ozdek A, Samim, E, Bayiz U, et al. Antrochoanal polyps in children. Int J Pediatr Otorhinolaryngol 2002;65:213-8. https://doi. org/10.1016/S0165-5876(02)00153-2

22 Bozzo C, Garrel R, Meloni F, et al. Endoscopic treatment of antrochoanal polyps. Eur Arch Otorhinolaryngol 2007;264:145-50. https:// doi.org/10.1007/s00405-006-0175-y

23 Kaushal A, Vaid L Singh PP. Antrochoanal polyp - validating its origin and management by Endonasal Endoscopic Sinus Surgery (EESS). Indian J Otolaryngol Head Neck Surg 2001;53:301-3. https:// do.org/10.1007/BF02991554

24 Franche GL, Granzotto EH, De Borba AT, et al. Endoscopic polipectomy with middle meatal antrostomy for antrochoanal polyp treatment. Braz J Otorhinolaryngol 2007;73:689-92. https://doi.org/10.1590/ S0034-72992007000500016

25 Drake-Lee AB. Nasal polyps. In: Derr AG, Mackay IS, Bull TR, editors. Scott-Brown's otolaryngology: rhinology. Sixth Edition. Oxford: Butterworth-Heinemann; 1997. pp. 1-15.

26 Soh KB, Tan KK. Sphenocoanal polyps in Singapore: diagnosis and current management. Singapore Med J 2000;41:184-7.

27 Berg O, Carenfelt B, Silfversward C, et al. Origin of choanal polyp. Arch Otolaryngol Head Neck Surg 1988;114:1270-1. https://doi. org/10.1001/archotol.1988.01860230064025

28 Deka RC. Antrochoanal polyp: Its pathogenesis origin and management by functional endonasal endoscopic surgery. Indian J Otolaryngol Head Neck Surg 1999;51:33-5. https://doi.org/10.1007/ BF02996841

29 Stammberger H, Posawetz W. Functional endoscopic sinus surgery. Concept, indications and results of the Messerklinger technique. Eur Arch Otorhinolaryngol 1990;247:63-76. https://doi.org/10.1007/ BF00183169

30 Freitas MR, Giesta RP, Pinheiro SD, et al. Antrochoanal polyp: a review of sixteen cases. Braz J Otorhinolaryngol 2006;72:831-5. https://doi.org/10.1590/S0034-72992006000600016

31 Chaiyasate S, Roongrotwattanasiri K, Patumanond J, et al. Antrochoanal polyps: how long should follow-up be after surgery? Int J Otolaryngol 2015;2015:297417-25. https://doi.org/10.1155/2015/297417 